\title{
PENGETAHUAN PESERTA PROGRAM PENDIDIKAN DOKTER SPESIALIS NEUROLOGI INDONESIA TENTANG SEMIOLOGI BANGKITAN EPILEPSI
}

\author{
INDONESIAN NEUROLOGY SPECIALIST EDUCATION PROGRAM KNOWLEDGE ABOUT \\ EPILEPTIC SEIZURE SEMIOLOGY
}

Suryani Gunadharma, * Yovita Stevina, * Anam Ong, * Siti Aminah, * Lisda Amalia, * Uni Gamayani*

\section{ABSTRACT}

Introduction: Seizure semiology is an effective method for syndrome diagnosis, especially when electroencephalogram (EEG) and brain magnetic resonance imaging (MRI) cannot provide sufficient information. Diagnosis of clinical epilepsy based on semiology required a comprehensive knowledge especially for neurology residents as candidate of neurology specialist.

Aim: To assess the knowledge of Indonesian neurology resident about seizure semiology.

Methods: This observational descriptive study was conducted from 4 choosen university in Indonesia from February to September 2019. Participants were neurology residents from $1^{\text {st }}$ semester to $8^{\text {th }}$ semester. Participants were asked to fill in that quetionnaire consist of 6 questions about the teaching of seizure semiology in their university. Five ictal videos were presented to be analyzed for semiology, lateralization, and localization. These videos were chosen by 3 epilepsy consultants from different universities.

Results: The participants consist of 135 residents, 16 in the $1^{\text {st }}$ semester, 21 in the $2^{\text {nd }}, 18$ in the $3^{\text {rd }}, 14$ in the $4^{\text {th }}, 14$ in the $5^{\text {th }}, 15$ in the $6 t^{h}, 19$ in the $7^{\text {th }}, 18$ in the $8^{\text {th }}$ semester. Video semiology were already lectured from the $3^{\text {rd }}$ semester in $66.7 \%-83 \%$. Only 30.3\% of semiology features from 5 videos can be recognized by the participants, semiology knowledge was improved from $2^{\text {nd }}$ semester. An average of $55.6 \%$ participants could answer lateralization and $52 \%$ localization.

Discussion: Neurology resident knowledge about seizure semiology is still insufficient, improvement and uniformity in teaching methodology of semiology is needed.

Keywords: Indonesian neurology resident, knowledge, seizure semiology

\section{ABSTRAK}

Pendahuluan: Semiologi bangkitan epilepsi merupakan cara yang efektif untuk menentukkan sindrom epilepsi terutama ketika electroencephalogram (EEG) dan magnetic resonance imaging (MRI) kepala tidak dapat memberikan cukup informasi. Untuk menegakkan diagnosis epilepsi berdasarkan semiologi dibutuhkan pengetahuan yang cukup, terutama untuk peserta program pendidikan dokter spesialis-1 (PPDS-1) neurologi Indonesia.

Tujuan: Untuk mengukur pengetahuan peserta PPDS-1 neurologi Indonesia tentang semiologi bangkitan epilepsi.

Metode: Penelitian deskriptif observasional ini dilakukan di 4 universitas terpilih di Indonesia pada bulan FebruariSeptember 2019. Subjek penelitian diminta mengisi kuesioner yang terdiri dari 6 pertanyaan tentang pengajaran semiologi bangkitan di pusat pendidikan masing-masing. Subjek juga diminta menentukan poin semiologi, lateralisasi dan lokalisasi dari lima video bangkitan yang telah dipilih oleh 3 orang dokter spesialis neurologi konsultan epilepsi dari 3 pusat pendidikan yang berbeda, namun dari tempat subjek-subjek penelitian.

Hasil: Subjek penelitian terdiri dari 135 residen, 16 di semester 1, 21 di semester 2, 18 di semester 3, 14 di semester 4, 14 di semester 5, 15 di semester 6, 19 di semester 7, 18 di semester 8. Kuliah semiologi menggunakan video sudah diberikan mulai semester 3 pada $66,7-83 \%$ subjek. Rerata hanya 30,3\% jawaban benar poin semiologi yang dapat disebutkan oleh subjek, pengetahuan ini mengalami peningkatan mulai dari semester 2. Sebanyak $55,6 \%$ subjek dapat menjawab benar lateralisasi dan $52 \%$ menjawab benar lokalisasi.

Diskusi: Pengetahuan peserta PPDS-1 tentang semiologi bangkitan epilepsi masih kurang sehingga diperlukan perbaikan dan keseragaman metodologi pengajaran untuk semiologi bangkitan epilepsi.

Kata kunci: Pengetahuan PPDS, PPDS neurologi Indonesia, semiologi bangkitan

*Departemen Neurologi FK Universitas Padjajaran/RSUP Dr. Hasan Sadikin, Bandung. Korespondensi: suryanig@yahoo.com.

\section{PENDAHULUAN}

Epilepsi merupakan kelainan neurologi yang umum ditemui. ${ }^{1-2}$ Penegakan diagnosis klinis epilepsi tidak mudah. Tingkat kesalahan diagnosis epilepsi dapat mencapai $20-31 \%$ sehingga memberikan dampak buruk bagi pasien. ${ }^{2-3}$ Pemahaman klinisi terhadap penyakit epilepsi diperlukan bagi peserta program pendidikan dokter spesialis-1 (PPDS-1) neurologi agar dapat melakukan penegakan diagnosis yang tepat.

Standar kompetensi dokter spesialis neurologi 2015 dijadikan sebagai acuan dalam 
menyelenggarakan aktivitas pendidikan dan sebagai pedoman dalam penentuan kelulusan PPDS-1. Saat ini kompetensi dasar untuk tata laksana bangkitan dan epilepsi mewajibkan PPDS-1 mampu menyimpulkan diagnosis bangkitan berdasarkan gambaran klinis, juga mampu menyimpulkan jenis atau sindrom epilepsi yang dialami pasien. Untuk mencapai kompetensi tersebut, diperlukan pengetahuan tentang semiologi bangkitan. ${ }^{1,4}$ Capaian pembelajaran yang diharapkan terutama pada PPDS-1 tingkat akhir hendaknya sampai pada tingkat tinggi (high order thinking), mampu mencapai kemampuan analisis pada taksonomi Bloom. ${ }^{5}$

Semiologi bangkitan adalah ilmu yang mempelajari manifestasi klinis bangkitan dan merupakanlangkahawal terpenting untukmenentukan lateralisasi dan lokalisasi dari zona epileptogenik. ${ }^{6-7}$ Semiologi bangkitan dapat menunjukkan lateralisasi sebesar $73 \%$ dan lokalisasi sebesar $80 \%{ }^{8}$ Gelombang interiktal pada perekaman scalp EEG hanya dapat menunjukkan lateralisasi $60 \%$ dan lokalisasi $66,9 \%{ }^{8}$

Pengetahuan klinis merupakan faktor yang berperan penting dalam menganalisis semiologi, maka penelitian ini dilakukan untuk melihat pengetahuan peserta PPDS-1 neurologi Indonesia tentang semiologi bangkitan epilepsi. ${ }^{9}$

\section{TUJUAN}

Untuk mengukur pengetahuan peserta PPDS1 neurologi Indonesia dalam menentukan semiologi bangkitan epilepsi.

\section{METODE}

Penelitian potong lintang dengan teknik nonprobability dan purposive sampling dilakukan dari bulan Februari sampai September 2019. Subjek penelitian ini terdiri dari peserta PPDS-1 neurologi dari 4 universitas. Kriteria inklusi pada penelitian ini adalah peserta PPDS-1 neurologi dari semester 1 hingga semester 8 yang sedang berada di tempat ketika penelitian berlangsung (tidak sedang menjalankan pelayanan kepada pasien atau melakukan tugas luar rumah sakit) dan bersedia mengikuti penelitian. Kriteria eksklusi pada penelitian ini adalah peserta PPDS-1 neurologi yang tidak mengisi lembar pengisian dengan lengkap atau dengan tulisan yang tidak terbaca.
Peneliti datang ke masing-masing pusat pendidikan di waktu yang berbeda. Subjek penelitian diminta mengisi kuesioner berisi 6 pertanyaan yang menggambarkan pengajaran epilepsi dari pusat pendidikan masing-masing dan melakukan analisis semiologi, lateralisasi dan lokalisasi dari lima video bangkitan.

Kuesioner telah kami buktikan valid dan reliabel pada peneletian pendahuluan yang belum dipublikasikan. Video bangkitan telah divalidasi oleh tiga orang dokter spesialis neurologi konsultan epilepsi dari tiga pusat pendidikan yang berbeda. Video bangkitan diambil dari video EEG di Rumah Sakit Hasan Sadikin tahun 2016-2018. Dipilih video bangkitan yang memiliki durasi singkat (2-3 menit) sehingga dapat mencakup keadaan preiktal hingga pascaiktal yang jelas, kualitas rekaman baik, suara jelas, semiologi beragam, dan mewakili kasus yang sering ditemui pada pasien epilepsi dewasa. Ditentukan lima buah video bangkitan yang paling memenuhi kriteria dan diurut secara acak. Epilepsi lobus temporal merupakan kasus tersering, namun memiliki durasi pascaiktal yang panjang sehingga hanya terpilih satu video. Epilepsi lobus frontal merupakan kasus tersering kedua dengan durasi bangkitan yang singkat sehingga dipilih empat video, sedangkan lobus parietal dan oksipital merupakan kasus terjarang dengan bentuk semiologi yang sulit tergambarkan hanya dari video sehingga tidak terpilih.

Analisis video meliputi analisis semiologi, lateralisasi, dan lokalisasi dari zona simptomatogenik. Analisis semiologi ditampilkan berdasarkan jumlah jawaban benar dan persentase dari total skoring poinpoin semiologi. Analisis lateralisasi dan lokalisasi disajikan dalam bentuk jumlah dan persentase subjek yang menjawab benar dari pertanyaan yang diajukan.

Penelitian ini sudah mendapat persetujuan etik dari Komisi Etik Penelitian Universitas Padjajaran No. 1068/UN6.KEP/EC/2019.

\section{HASIL}

Jumlah subjek penelitian adalah 135 orang PPDS-1. Rerata usia subjek penelitian adalah $31,60 \pm 3,145$ tahun. Terdapat sebaran yang cukup merata dari jumlah subjek per semester (Tabel 1). 
Tabel 1. Karakteristik Subjek Penelitian $(n=135)$

\begin{tabular}{lc}
\hline Karakteristik & n (\%) \\
\hline Jenis Kelamin & \\
- $\quad$ Laki-laki & $58(43)$ \\
- $\quad$ Perempuan & $77(57)$ \\
Usia (tahun), Rerata \pm SD & $31,60 \pm 3,145$ \\
Semester & \\
- Semester 1 & $16(11,3)$ \\
- Semester 2 & $21(14,9)$ \\
- Semester 3 & $18(12,8)$ \\
- Semester 4 & $14(9,9)$ \\
- Semester 5 & $14(9,9)$ \\
- Semester 6 & $15(10,6)$ \\
- $\quad$ Semester 7 & $19(13,5)$ \\
- $\quad$ Semester 8 & $18(12,7)$ \\
\hline SD: standar deviasi.
\end{tabular}

Data dari kuesioner menunjukkan $89,8 \%$ subjek pernah mendapat kuliah epilepsi dan juga sudah diperkenalkan dengan istilah semiologi selama masa PPDS-1 (semester 1-semester 8). Kuliah disertai video tentang semiologi sudah diberikan mulai semester 3 pada $66,7-83 \%$. Diagnosis sindrom sudah pernah dilakukan oleh 55,6\%-85,7\% subjek mulai dari semester 3 (Tabel 2).
Seluruh subjek penelitian tidak dapat menyebutkan poin semiologi secara utuh $(100 \%)$, nilai median pencapaian hanya $30,3 \%$, dan kemampuan meningkat mulai dari semester 2 sampai semester 8. Kemampuan rerata menentukan lateralisasi dan lokalisasi keseluruhan peserta PPDS-1 adalah 55,6\% untuk lateralisasi dan 52\% untuk lokalisasi (Tabel 3).

\section{PEMBAHASAN}

Tingkat nilai pengetahuan dikategorikan atas tingkat pengetahuan baik (76-100\%), cukup (60$75 \%)$, dan kurang $(<60 \%) .{ }^{10}$ Menurut taksonomi Bloom, pengetahuan memiliki 6 tingkat, yaitu mengingat (C1), memahami (C2), mengaplikasikan (C3), menganalisis (C4), mengevaluasi (C5), dan mengkreasi (C6). ${ }^{5}$ Pendidikan neurologi di Indonesia dibagi menjadi tiga tahap yaitu tahap pembekalan, tahap magang dan tahap mandiri. ${ }^{4}$ Tahap pembekalan yaitu semester 1, seorang PPDS-1 sudah diberikan ilmu dasar anatomi, fisiologi serta penyakit dasar neurologi sehingga diharapkan sudah tahu tentang dasar penyakit epilepsi (C1). Tahap magang yaitu semester 2 sampai 6, seorang PPDS-1 sudah memperdalam kasus neurologi beserta pemeriksaan

Tabel 2. Kuesioner Tentang Pengajaran Semiologi Bangkitan $(n=135)$

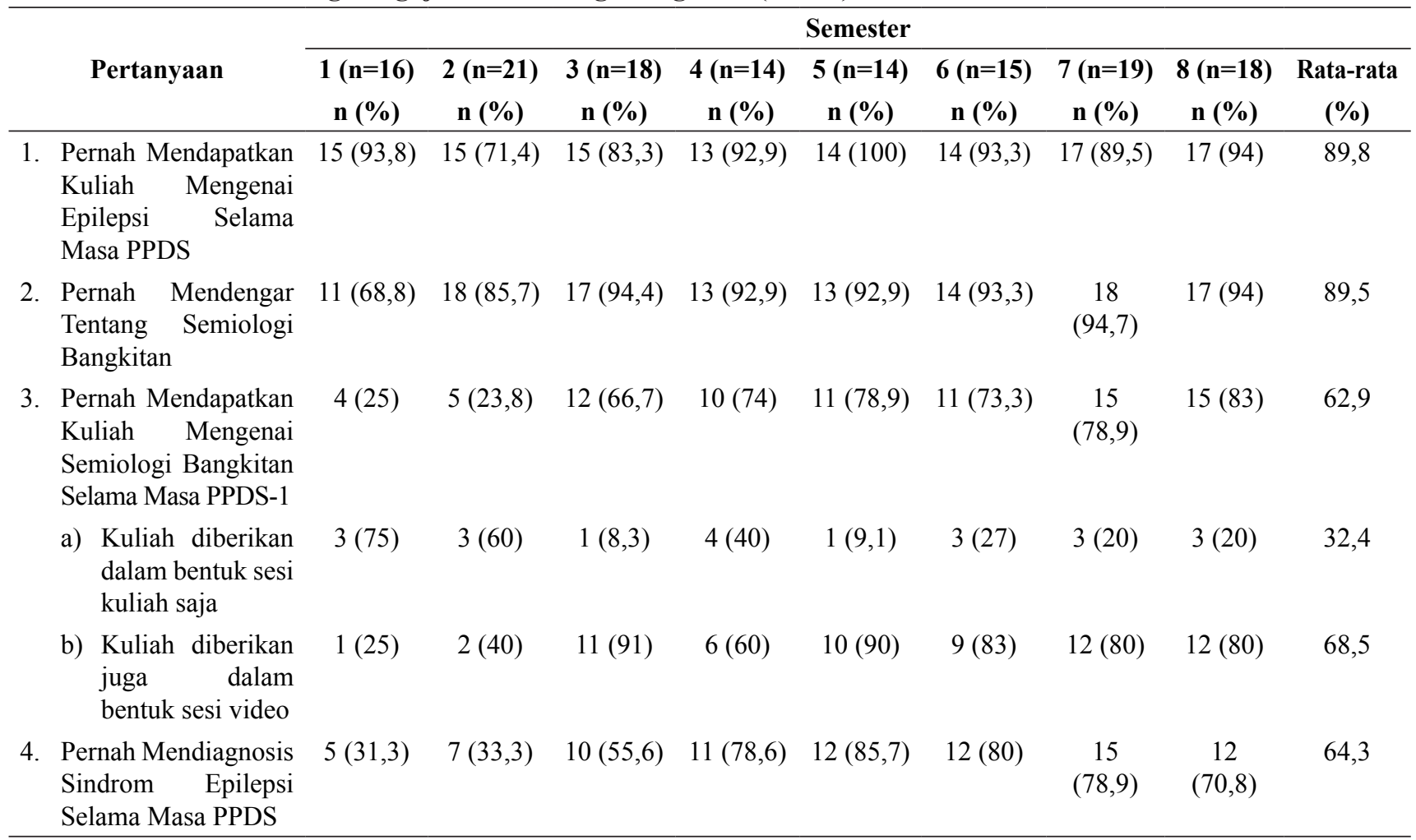

PPDS: program pendidikan dokter spesialis. 
Tabel 3. Rerata Persentase Nilai Poin Semiologi, Jawaban Benar Lateralisasi, dan Jawaban Benar Lokalisasi (n=135)

\begin{tabular}{cccc}
\hline Tingkat Semester & Nilai Poin Semiologi (\%) & Lateralisasi (\%) & Lokalisasi (\%) \\
\hline Semester 1 & 20 & 50,02 & 39 \\
Semester 2 & 26 & 55,04 & 52 \\
Semester 3 & 25 & 56 & 43 \\
Semester 4 & 25 & 58,4 & 58 \\
Semester 5 & 30 & 60,4 & 56 \\
Semester 6 & 40 & 58,9 & 55 \\
Semester 7 & 35 & 54,8 & 56 \\
Semester 8 & 41 & 51,06 & 57 \\
Rata-rata & 30,3 & 55,6 & 52 \\
\hline
\end{tabular}

penunjang serta sudah melakukan aplikasi pada pasien poli rawat jalan maupun rawat inap, sehingga diharapkan PPDS-1 pada tahap magang dapat memahami lebih dalam tentang semiologi bangkitan dan dapat mengaplikasikan pada pasien (C2-C3). Tahap mandiri pada semester 7 dan 8 , PPDS- 1 sudah dipercaya untuk menjadi chief resident dan memiliki kemampuan kerja mandiri di rumah sakit jejaring, sehingga diharapkan sudah dapat menentukan poin semiologi dan melakukan analisis menjadi lateralisasi dan lokalisasi pada pasien bangkitan, dapat memadukan dengan EEG dan MRI untuk menentukan diagnosis sindrom epilepsi dan siap menjalani uji kompetensi (C4). ${ }^{4}$ PPDS-1 terutama semester 8 harus memiliki pengetahuan berpikir tingkat tinggi (high order thinking) yaitu minimal $\mathrm{C} 4$ dan memiliki nilai minimal cukup (60-75\%) yang belum tampak pada hasil penelitian ini. . $^{510}$

Sembilan puluh tiga koma delapan persen subjek tahap pembekalan (semester 1) sudah pernah mendengar tentang semiologi bangkitan. Pada tahap magang (semester 2-6), terlihat peningkatan pengetahuan (5 sampai 20\%) dalam menentukan poin semiologi dari video bangkitan, menunjukkan subjek sudah mulai dapat mengaplikasikan teori yang didapat walaupun hasilnya masih kurang. Tahap mandiri (semester 7 dan 8) diharapkan dapat menjawab poin semiologi dengan target cukup (60-75\%), namun tidak menunjukkan peningkatan pengetahuan yang berarti. Walaupun PPDS-1 tahap mandiri sudah diberikan wewenang untuk melakukan pemeriksaan pasien secara mandiri, namun pada tahap ini PPDS1 juga mulai melakukan penelitian dan mengejar tugas-tugas akhir serta jarang mendapatkan kuliah. Kemungkinan hal ini menjadi penyebab tidak adanya peningkatan nilai pengetahuan dalam menentukan poin semiologi pada penelitian ini.

Melihat bentuk bangkitan secara langsung tentu akan berbeda dibandingkan dengan melihat video dimana klinisi dapat berinteraksi langsung saat melihat bangkitan yang sedang berlangsung, tetapi tidak saat melihat video. ILAE 2019 menyatakan kompetensi dokter spesialis neurologi harus sampai dalam tahap dapat menentukan semiologi dari anamnesis maupun video bangkitan. ${ }^{11}$ Tidak semua poin semiologi memiliki nilai lateralisasi dan lokalisasi, namun dengan kemampuan mengumpulkan poin-poin semiologi dan pengetahuan untuk melakukan analisis dari semiologi diharapkan dapat meningkatkan ketepatan dalam menentukan lateralisasi dan lokalisasi. ${ }^{12}$ Kenyataannya dari penelitian ini, subjek penelitian terutama pada semester 8 , belum seluruhnya dapat melakukan analisis video secara utuh (rerata 55,6\% subjek dapat menjawab lateralisasi dan $52 \%$ dapat menjawab lokalisasi dengan benar).

Terdapat beberapa hal yang memengaruhi pengetahuan yaitu usia, pendidikan, pengetahuan dan minat. Pada penelitian ini usia subjek dalam usia puncak (20-40 tahun) dimana kondisi fisik dan intelektual baik. ${ }^{13}$ Dari kuesioner didapatkan pendidikan semiologi pada subjek penelitian sudah diberikan dalam bentuk sesi kuliah dan video mayoritas sejak semester 3. Pengetahuan semiologi yang masih kurang terutama pada semester 8 kemungkinan akibat kurangnya pengalaman dalam menganalisis semiologi dari pasien atau karena kurangnya variasi kasus bangkitan yang pernah ditangani. ${ }^{14}$ Selain itu faktor lingkungan seperti fasilitator, fasilitas belajar, kurikulum, dan metode 
pengajaran turut memengaruhi proses belajar. ${ }^{10,15}$

Penelitian ini memiliki beberapa keterbatasan yaitu bahasa yang digunakan dalam video bangkitan yang ditampilkan sebagian menggunakan bahasa daerah Sunda, keterbatasan ini dikurangi dengan menerjemahkan secara langsung ke dalam bahasa Indonesia saat video ditayangkan. Variasi dalam pemilihan video bangkitan kurang, tidak ada sindrom pada anak dan bangkitan umum. Waktu dan metode pembelajaran untuk kurikulum kejang dan epilepsi berbeda-beda setiap pusat pendidikan, demikian juga dengan lama stase EEG/epilepsi berbeda-beda di setiap universitas sehingga juga akan berpengaruh pada jumlah paparan kasus, hal ini tentu akan berpengaruh terhadap hasil penelitian.

Pengetahuan semiologi bangkitan dapat ditingkatkan dengan cara berlatih melalui video bangkitan maupun melihat pasien secara langsung. Kuliah tentang semiologi bangkitan diberikan kembali pada semester 7 dan 8 untuk mempersiapkan ujian kompetensi sebagai dokter spesialis neurologi. Disarankan dibuat keseragaman kurikulum epilepsi secara nasional termasuk lama stase dan jumlah kasus yang perlu dilihat saat stase bagi program spesialis-1 neurologi di Indonesia agar mencapai target yang diharapkan oleh Kolegium Neurologi.

\section{KESIMPULAN}

Pengetahuan PPDS-1 tentang semiologi bangkitan epilepsi masih kurang.

\section{DAFTAR PUSTAKA}

1. Kusumastuti K, Gunadharma S, Kustowati E, editor. Pedoman tatalaksana epilepsi. Edisi 6. Jakarta: Airlangga University Press; 2019. h.13,59.

2. National Institute for Health and Care Excellence. The epilepsies: the diagnosis and management of the epilepsies in adults and children in primary and secondary care. NICE Clinical Guideline; 2018.

3. Levina TR, Gunadharma S, Arifin S. Misdiagnosis of epilepsy attributed to inadequate history taking. Althea Med J. 2016;3(2):304-8.
4. Islam MS, Harsono, Poerwadi T, Samatra P, Dewati E, Islam WR, editor. Standar kompetensi dokter spesialis neurologi Indonesia (Revisi tahun 2015). Malang: Kolegium Neurologi Indonesia; 2015. h.1516,51

5. Anderson LW, Krathwohl DR. Kerangka landasan untuk pembelajaran, pengajaran, dan asesmen revisi taksonomi. Yogyakarta: Pustaka Pelajar; 2010. h.406.

6. Chauvel P, McGonigal A. Emergence of semiology in epileptic seizures. Epilepsy Behav. 2014;38:94-103.

7. Lüders H, Fernandez G, Akamatsu N, Amina S, Arzimanoglou A. Classification of paroxysmal events and the four-dimensional epilepsy Classification System. Epileptic Disord. 2019;21(1):1-29.

8. Elwan S, Alexopoulos A, Silveira, Prakash. Lateralizing and localizing value of seizure semiology: Comparison with scalp EEG, MRI and PET in patients successfully treated with resective epilepsy surgery. Seizure. 2018;61:203-8.

9. Seneviratne U, Rajendran D, Brusco M, Phan TG. How good are we at diagnosing seizures based on semiology? Epilepsia. 2012;53(4):63-6.

10. Arikunto S. Prosedur penelitian: suatu pendekatan praktik. Edisi VI. Jakarta: Rineka Cipta; 2010. h.1405,190-5.

11. Blümcke I, Arzimanoglou A, Beniczky S, Wiebe S. Roadmap for a competency-based educational curriculum in epileptology: report of the epilepsy education task force of the international league against epilepsy. Epileptic Disord. 2019;21(2):12940.

12. Jahn MM, Girvin JP. Seizure semiology: value in identifying seizure origin. Can J Neurol Sci. 2008;35(1):22-30.

13. Hurlock EB. Psikologi perkembangan: suatu pendekatan sepanjang rentang kehidupan. Edisi 5 Jakarta: Erlangga; 2011. h.245-60.

14. Tufenkjian K, Lüders HO. Seizure semiology: Its value and limitations in localizing the epileptogenic zone. J Clin Neurol. 2012;8:243-7.

15. Dalyono M. Psikologi pendidikan. Jakarta: Rineka Cipta; 2009. h. 55-60. 